\title{
Incidence and predictors of Uveitis in juvenile idiopathic arthritis in a Nordic long-term cohort study
}

\author{
Ellen Nordal $^{1 *}$ (D), Veronika Rypdal ${ }^{1}$, Terje Christoffersen ${ }^{2}$, Kristiina Aalto $^{3}$, Lillemor Berntson ${ }^{4}$, Anders Fasth $^{5}$, \\ Troels Herlin ${ }^{6}$, Susan Nielsen ${ }^{7}$, Suvi Peltoniemi ${ }^{3}$, Bjørn Straume ${ }^{8}$, Marek Zak ${ }^{7}$, Marite Rygg ${ }^{9}$ and for the Nordic Study \\ Group of Pediatric Rheumatology (NoSPeR)
}

\begin{abstract}
Background: The incidence of uveitis associated with juvenile idiopathic arthritis (JIA) varies around the world. Our aim was to investigate the incidence and predictors of uveitis in a Nordic population-based cohort.

Methods: Consecutive JIA cases from defined geographical areas in Denmark, Finland, Sweden and Norway with disease onset between January 1997 to June 2000 were followed for median 98 months in this prospective longitudinal cohort study. Potential clinical and immunological predictors of uveitis were identified with logistic regression analysis.

Results: Uveitis occurred in 89 (20.5\%) of the 435 children with regular ophtalmologic follow-up among the 500 included. Chronic asymptomatic uveitis developed in 80 and acute symptomatic uveitis in 9 children. Uveitis developed at a median interval of 0.8 (range -4.7 to 9.4) years after onset of arthritis. Predictors of uveitis were age $<7$ years at JIA onset (Odds ratio (OR) 2.1, 95\% confidence interval (CI) 1.3 to 3.5), presence of antihistone antibodies (AHA) > $15 \mathrm{U} / \mathrm{ml}$ (OR 4.8 (1.8 to 13.4)) and antinuclear antibodies (ANA) (OR 2.4 (1.5 to 4.0)). Mean combined $\mathrm{lgM} / \mathrm{lgG}$ AHA was significantly higher in the uveitis group $(19.2 \mathrm{U} / \mathrm{ml})$ than in the non-uveitis group $(10.2 \mathrm{U} / \mathrm{ml})$ $(p=0.002)$. Young age at JIA onset predicted uveitis in girls $(p<0.001)$, but not in boys $(p=0.390)$.

Conclusion: Early-onset arthritis and presence of AHA in girls, as well as presence of ANA in both genders, were significant predictors of chronic uveitis. The high incidence of uveitis in this long-term Nordic JIA cohort may have severe implications in a lifelong perspective.
\end{abstract}

Keywords: Juvenile idiopathic arthritis, Uveitis, Epidemiology, Biomarkers, Histones, Antinuclear antibody

\section{Background}

Uveitis is the most common extra-articular manifestation of juvenile idiopathic arthritis (JIA). This sightthreatening condition contributes significantly to the disease burden of JIA $[1,2]$. Chronic insidious uveitis in JIA is often asymptomatic, and it is a major challenge to diagnose the condition as early as possible for prompt and adequate treatment $[3,4]$. The diagnosis may be obvious in cases with acute uveitis [5], but the challenge

\footnotetext{
* Correspondence: ellen.nordal@icloud.com

'Department of Pediatrics, University Hospital of North Norway, and Department of Clinical Medicine, UiT the Arctic University of Norway, Tromsø, Norway

Full list of author information is available at the end of the article
}

remains to provide optimal screening programs and treatment to minimize long-term complications in all forms of JIA-associated uveitis. The reported prevalence of uveitis in JIA varies highly, and ethnic and geographic differences seem to exist. Recent publications show a prevalence of $8-25 \%$ in most Caucasian populations $[6,7]$, while some studies from other continents show lower percentage of uveitis, 1 to $7 \%[8,9]$. Young age at onset of arthritis and presence of ANA were predictors of uveitis in most studies [3, 10-12]. In some larger cohort studies and registries, oligoarticular onset category and female gender were also statistically significant predictors of uveitis, but with less clinical impact $[3,13]$. 
Histones are subcomponents of chromatin where these basic DNA-binding proteins are found in highly organized nucleosomal particles [14]. Antihistone antibodies (AHA) are among the ANA subtypes identified in subsets of children with JIA, while other subtypes associated with connective tissue diseases such as antiDNA, anti-RNP, anti-SSA and anti-SSB antibodies are rarely found $[15,16]$. AHA were reported to be associated with early-onset JIA, oligoarthritis and uveitis [17]. We showed previously that AHA is a significant predictor of chronic uveitis in a Norwegian JIA cohort [11]. Whether this association is merely an epiphenomenon is not yet known, although new interest for histones in autoimmune diseases has emerged through recent epigenetic findings $[18,19]$.

A longitudinal cohort study of JIA in a populationbased setting in the Nordic countries started in 1997 and is still ongoing $[20,21]$. The ophthalmologic data of a follow-up 8 years after disease onset of this Nordic JIA cohort were analyzed in the present study. The main objective was to describe the incidence and the predictors of uveitis in JIA during the first decade after disease onset. We also wanted to extend the previous Norwegian pilot study to the Nordic JIA cohort regarding the presence of histone antibodies in patients with JIA with and without uveitis, respectively.

\section{Methods}

\section{Patients}

In this longitudinal study, children with long-term ophthalmologic follow-up were selected from a prospective multicentre Nordic JIA cohort. The original multicentre cohort consisted of consecutive children with newly diagnosed JIA and disease onset between January 1, 1997 to June 30, 2000 from defined geographical areas of Denmark, Finland, Norway and Sweden aiming for the cohort to be population-based [20]. Clinical information including family history, assessment of disease activity, self-reported questionnaires and information from ophthalmology visits was registered per protocol at baseline and at 1 to 3 year intervals. Detailed description of the methods of patient accrual and data collection has been published previously [21].

At the final study visit, at least 7.0 years (median 98 months, range 84-147 months) after disease onset, extended data including information from the most recent ophthalmologic visit was collected. The interval of ophthalmologic visits was every 2-3 months the first 2 years, then longer intervals according to time after disease onset and JIA category. The intervals were in line with the guidelines for uveitis screening at each center, based on international uveitis screening guidelines. Uveitis was registered as present and active, when the ophthalmologist prescribed treatment for inflammation in the uvea. Uveitis was classified according to the recommendations by the Standardization of Uveitis Nomenclature (SUN) working group [22]. Uveitis was classified as "acute"; symptomatic with acute onset, sometimes recurrent course but of limited duration, or "chronic"; insidious onset, mainly asymptomatic with chronic recurrent or persistent course. Collected data also included locally analyzed HLA-B27, antinuclear antibodies (ANA) and rheumatoid factor (RF), and a positive result of the latter two had to be confirmed, at least 3 months apart. Each physician interpreted the results of ANA and $\mathrm{RF}$ analysis as positive or negative according to the reference values of their local laboratory; the cut-off value for a positive test was $\geq 1 / 80$ in Tromsø, Trondheim and parts of Sweden, $\geq 1 / 320$ in Finland, and $\geq 1 / 160$ in Copenhagen, Århus and some parts of Sweden. ANA was measured using immunofluorescence on HEp-2 cells. Serum was taken at a median of 4 (1st quartile of 2 , 3rd quartile of 7) months after the disease was diagnosed, frozen and stored at $-70{ }^{\circ} \mathrm{C}$ in aliquots to avoid repeated freeze-thaw cycles. AHA were detected with Varelisa Histone Antibodies Enzyme Induced Assay (EIA) kit for antihistone IgM/IgG antibodies using a combined IgM/IgG conjugate (Phadia Diagnostics, Freiburg, Germany) at UIT The Arctic University of Norway, Tromsø, Norway. Tests were run according to the manufacturer's instructions [23]. According to the kit instructions a level $\geq 30 \mathrm{U} / \mathrm{ml}$ is considered positive, 15-29 U/ml borderline, and < $15 \mathrm{U} /$ $\mathrm{ml}$ negative, based on a test population of 432 healthy adults, normative values are not given for children. In the present study, we investigated $\geq 15 \mathrm{U} / \mathrm{ml}$ as a positive threshold based on our previous study reporting a mean concentration of $4.3 \mathrm{U} / \mathrm{ml}$ in 58 healthy children utilizing the same Varelisa Histone EIA-kit [11]. The presence of AHA in a Norwegian JIA cohort, also including the Norwegian subsets of this Nordic JIA cohort, has previously been reported and was therefore not included here [11]. No sera were available from the Finnish participants, and subsequently analyses of the AHA were performed only in the Swedish and Danish sera.

Approval from medical research ethical committees and data protection authorities was granted according to the regulations of each participating country, in Norway from Regional Committee for Medical and Health Research Ethics NORD, number 53/96. Oral informed assent was obtained from all children. Written informed consent was obtained from parents of children aged $<16$ years and from the children if aged $\geq 16$ years.

\section{Statistical analyses}

The study report followed the STROBE guidelines [24]. Statistical analyses were performed using the STATA version 14 software (STATA Corp., College Station, TX, USA). Descriptive statistics were used to summarize 
clinical characteristics of the population and disease activity measures. The chi-square test was used as appropriate for comparison of categorical variables. The Student's $t$-test was used to compare means in continuous outcomes between groups, and Mann-Whitney rank sum test for comparison of medians for skewed data. A logistic regression analysis of baseline characteristics was performed to calculate odds ratio for developing uveitis. The $p$-value $<0.05$ was considered significant.

\section{Results}

Regular ophthalmologic follow-up for more than 7 years was available in $435(87.0 \%)$ of the 500 children included in the prospective multi-centre Nordic JIAcohort; 60 children were lost to follow-up, and in 5 children long-term ophthalmological data were missing. Baseline clinical characteristics of the group with or without long-term follow-up were mostly similar and have previously been published [21].

\section{Incidence}

Uveitis developed in 89 (20.5\%) of the 435 children. Clinical characteristics at baseline according to the presence of acute and chronic uveitis is shown in Table 1. Among the 9 children with acute uveitis, 8 had enthesitis-related arthritis (ERA), and 7 were HLA-B27 positive. Chronic insidious uveitis developed in 80 (18.4\%) children. The cumulative incidence of uveitis according to the International League of Associations for Rheumatology (ILAR) categories is shown in Table 2. There were no uveitis in the systemic nor in the polyarticular RF positive categories, and highest incidence was noted in the juvenile psoriatic arthritis (35.7\%) and enthesitis-related arthritis (25.0\%) categories. The incidence of uveitis was significantly higher in Finland than in the other Nordic countries (Table 3). Finland also had the highest proportion of children with young age at onset of JIA, but neither gender, oligoarticular onset nor the prevalence of HLA-B27, ANA, or AHA showed any corresponding difference between countries.

Time from onset of arthritis to onset of uveitis is shown in Fig. 1, including 5 children in which uveitis was diagnosed before the arthritis, one of these had acute uveitis. Uveitis developed within the first year after onset of arthritis in 48 (53.9\%), within 4 years in 73 $(82.0 \%)$ of the children, and 4 children $(4.5 \%)$ had onset of uveitis more than 8 years after onset of arthritis, 2 of these had chronic asymptomatic uveitis. The number of children developing uveitis within the first year after onset of arthritis is 6 times the number developing uveitis during the second year, and 16 times the number during the fifth year. All together uveitis developed with an interval of median 0.8 (range -4.7 to 9.4 ) years after onset of arthritis, while chronic uveitis developed with a median interval of 0.7 (range -3.0 to 8.6 ) years after onset of arthritis.

Table 1 Clinical characteristics at the first study visit in 435 children in the Nordic juvenile idiopathic arthritis (JIA) cohort according to the presence of acute or chronic uveitis during $>7$ years of follow-up

\begin{tabular}{|c|c|c|c|c|c|c|c|c|}
\hline \multirow{3}{*}{ Female gender } & \multicolumn{2}{|c|}{ All children } & \multicolumn{2}{|c|}{ No uveitis } & \multicolumn{2}{|c|}{ Acute uveitis } & \multicolumn{2}{|c|}{ Chronic uveitis } \\
\hline & $\bar{N}$ & & $\mathrm{~N}$ & & $\mathrm{~N}$ & & $\bar{N}$ & \\
\hline & 435 & $286(65.8)$ & 346 & $227(65.6)$ & 9 & $4(44.4)$ & 80 & $55(68.8)$ \\
\hline Age at onset, median (1st, 3rd q) & 435 & $5.5(2.4,9.5)$ & 346 & $6.2(2.8,10)$ & 9 & $10.8(9.3,12.9)$ & 80 & $3.2(1.8,5.9)$ \\
\hline Oligoarticular onset ${ }^{\mathrm{a}}$ & 435 & $224(51.5)$ & 346 & $180(52.0)$ & 9 & $1(11.1)$ & 80 & $43(53.8)$ \\
\hline ANA positive & 427 & $116(27.2)$ & 340 & $79(23.2)$ & 9 & $0(0)$ & 78 & $37(47.4)$ \\
\hline $\mathrm{AHA}>15 \mathrm{U} / \mathrm{ml}$ & 134 & $23(17.2)$ & 112 & $14(12.5)$ & 3 & $1(33.3)$ & 19 & $8(42.1)$ \\
\hline RF positive & 424 & $10(2.4)$ & 336 & $9(2.7)$ & 9 & $1(11.1)$ & 79 & $0(0.0)$ \\
\hline HLA-B27 positive & 413 & $87(21.1)$ & 325 & $62(19.1)$ & 9 & $7(77.8)$ & 79 & $18(22.8)$ \\
\hline ESR, median (1st, 3rd q) & 354 & $14(8,28)$ & 276 & $14(8,26)$ & 8 & $23(10,41)$ & 70 & $16(9,36)$ \\
\hline CRP, median (1st, 3rd q) & 350 & $0(0,10)$ & 276 & $0(0,10)$ & 9 & $0(0,16)$ & 65 & $0(0,14)$ \\
\hline JADAS27, median (1st, 3rd q) & 194 & $5.1(2.0,11.0)$ & 157 & $5.0(2.0,9.8)$ & 7 & $10.4(5.6,14.9)$ & 30 & $3.8(1.6,12.5)$ \\
\hline CHAQ, median (1st, 3rd q)) & 273 & $0.3(0.0,1.0)$ & 222 & $0.4(0.0,1.0)$ & 8 & $0.4(0.1,1.2)$ & 43 & $0.3(0.0,1.0)$ \\
\hline DMARD use 2 nd visit ${ }^{\mathrm{b}}$ & 350 & $125(35.6)$ & 316 & $111(35.1)$ & 7 & $3(37.5)$ & 27 & $11(42.3)$ \\
\hline
\end{tabular}

Data are presented as numbers (\%), unless otherwise noted

ANA antinuclear antibodies measured by immunofluorescence on Hep-2 cells, and RF rheumatoid factor; two positive tests taken $>3$ months apart in participants with one or more tests taken, $A H A>15 \mathrm{U} / \mathrm{ml}$ antihistone antibodies lgM/lgG $>15 \mathrm{U} / \mathrm{ml}, H L A-B 27$ human leucocyte antigen B27, Age at onset age at onset of arthritis in years, ESR erythrocyte sedimentation rate, CRP C-reactive protein JADAS27 Juvenile arthritis disease activity score based on 27 joint count, CHAQ Child health assessment questionnaire

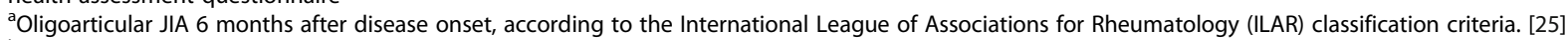
bercentage of DMARD = Disease modifying anti-rheumatic drugs including biological agents used within the 2nd visit (median 13 months (IQR 12-14)) in 350 children without uveitis at the time of the 2 nd study visit, differentiating into no uveitis, acute, or chronic uveitis during further follow-up 
Table 2 Presence of acute or chronic uveitis in the different JIA categories according to the International League of Associations for Rheumatology (ILAR) classification criteria at the final study visit in 435 children in the Nordic juvenile idiopathic arthritis (JIA) cohort

\begin{tabular}{llllll}
\hline \multicolumn{1}{c}{ JIA category } & $\begin{array}{l}\text { All children } \\
n=435(\% \text { of all) }\end{array}$ & $\begin{array}{l}\text { No uveitis } \\
n=346(\%)\end{array}$ & $\begin{array}{l}\text { Acute uveitis } \\
n=9(\%)\end{array}$ & $\begin{array}{l}\text { Chronic uveitis } \\
n=80(\%)\end{array}$ & $\begin{array}{l}\text { Cumulative total uveitis } \\
\text { incidence }(95 \% \mathrm{Cl})^{\mathrm{a}}\end{array}$ \\
\hline Systemic & $18(4.1)$ & $18(100.0)$ & $0(0)$ & $0(0)$ & $0(0,18.5)$ \\
Oligoarticular persistent & $131(30.1)$ & $106(80.9)$ & $0(0)$ & $25(19.1)$ & $19.1(12.7,26.9)$ \\
Oligoarticular extended & $78(17.9)$ & $62(79.5)$ & $0(0)$ & $16(20.5)$ & $20.5(12.2,31.2)$ \\
Polyarticular RF negative & $80(18.4)$ & $62(77.5)$ & $0(0)$ & $18(22.5)$ & $22.5(13.9,33.2)$ \\
Polyarticular RF positive & $3(0.7)$ & $3(100.0)$ & $0(0.0)$ & $0(0.0)$ & $0(0,70.8)$ \\
Juvenile psoriatic arthritis & $14(3.2)$ & $9(64.3)$ & $0(0.0)$ & $4(35.7)$ & $35.7(12.8,64.9)$ \\
Enthesitis-related arthritis & $48(11.0)$ & $36(75.0)$ & $8(16.7)$ & $12(19.0)$ & $25.0(13.6,39.6)$ \\
Undifferentiated arthritis & $63(14.5)$ & $50(79.4)$ & $1(1.6)$ & $20.6(11.5,32.7)$ \\
\hline
\end{tabular}

${ }^{\mathrm{a}} \mathrm{Cl}$, confidence interval

\section{Predictors of uveitis}

Young age at onset of JIA and ANA were significant predictors of uveitis (Tables 4 and 5 ). AHA $\geq 15 \mathrm{U} / \mathrm{ml}$ was found in $23(17.2 \%)$ and $\mathrm{AHA} \geq 30 \mathrm{U} / \mathrm{ml}$ in $10(7.5 \%)$ of the 134 participants with AHA analyses. AHA $\geq 30 \mathrm{U} / \mathrm{ml}$ was found in 3 of the 5 females with uveitis and AHA analyses. The presence of AHA $\geq 15 \mathrm{U} / \mathrm{ml}$ was significantly higher in children with uveitis than in children without (OR 4.8 (1.8 to 13.4)) (Table 4). Serum concentration of AHA IgM/IgG antibodies was significantly higher in the group with uveitis (mean $19.2 \mathrm{U} / \mathrm{ml}$ ) than in children without uveitis (mean $10.2 \mathrm{U} / \mathrm{ml}$ ) in the Swedish and Danish cohort with available sera for antihistone analyses ( $p=0.002$; chi-square, data not shown).

Neither gender, oligoarticular onset nor other ILAR categories predicted uveitis. Presence of HLA-B27 was borderline significant as a predictor of uveitis, primarily because there was a high presence of HLA-B27 among children with acute uveitis (Tables 1 and 4). There was no significantly reduced risk of developing uveitis in children that had started disease-modyfing antirheumatic drug (DMARD) treatment, including biologics, neither at the first (data not shown) nor at the second study visit (Tables 1 and 4), taking into account the start date of DMARDs and the date of diagnosis of uveitis. At the final study visit the percentage of children ever using DMARDs was higher in the uveitis group (78.7\%) compared to the group without uveitis (53.2\%) (data not shown), but the number of children receiving DMARDs to treat primarily their uveitis is not known. These analyses on DMARDs were also performed for methotrexate, showing the same result. There were no significant difference in incidence of uveitis in children that had used etanercept (18.5\%) during the disease course versus those that never used etanercept (20.7\%), $p=0.706$. Also the incidence of uveitis was similar in children that had used sulfasalazine (16.1\%) versus those that never used sulfasalazine (21.2\%), $p=0.361$. During the disease course, $14.3 \%$ of the cohort used sulfasalazine, while $12.4 \%$ used etanercept. The main predictors of uveitis in Table 4 were stratified for gender (Table 5). This analysis showed that girls with uveitis had a lower median age at onset of arthritis of 3.4 versus 6.8 in girls without uveitis $(p<0.001)$. The difference in age at onset was highly significant in girls, but not in boys $(p=0.390)$ (Tables 4 and 5). ANA was a significant predictor, both in girls and in boys (Table 4). Analysis stratified for gender showed that median median AHA was significantly higher in girls $(p=0.003)$, but not in boys $(p=0.794)$ (Table 5).

Table 3 Presence of uveitis, antinuclear antibodies, antihistone antibody levels and HLA-B27 according to country of origin in 435 children in the Nordic juvenile idiopathic arthritis (JIA) cohort

\begin{tabular}{|c|c|c|c|c|}
\hline & Denmark $n=91$ & Norway $n=105$ & Sweden $n=101$ & Finland $n=138$ \\
\hline No uveitis & $73(80.2)$ & $86(81.9)$ & $87(86.1)$ & $100(72.5)$ \\
\hline Acute uveitis & $3(3.3)$ & $4(3.8)$ & $1(1.1)$ & $1(0.7)$ \\
\hline Chronic uveitis & $15(16.5)$ & $15(14.3)$ & $13(12.9)$ & $37(26.8)$ \\
\hline Female gender & $62(68.1)$ & $67(70.5)$ & $67(66.3)$ & $83(60.1)$ \\
\hline Oligoarticular onset & $45(49.5)$ & $51(48.6)$ & $55(54.5)$ & $73(52.9)$ \\
\hline Age at onset & $4.8(2.2,9.3)$ & $5.9(2.8,9.9)$ & $6.9(3.2,11.3)$ & $5.1(2.3,8.7)$ \\
\hline ANA positive & $28(30.8)$ & $32(32.0)$ & $23(22.8)$ & $33(24.4)$ \\
\hline HLA-B27 positive & $14(15.6)$ & $29(27.6)$ & $20(21.5)$ & $24(19.2)$ \\
\hline
\end{tabular}

Data are numbers (percent) except median (1st and 3rd quartile) for Age at onset; age at onset of arthritis, $A N A$ antinuclear antibodies measured by immunofluorescence on Hep- 2 cells, two positive tests taken more than 3 months apart in participants with one or more tests takenm HLA-B27 human leucocyte antigen B27 


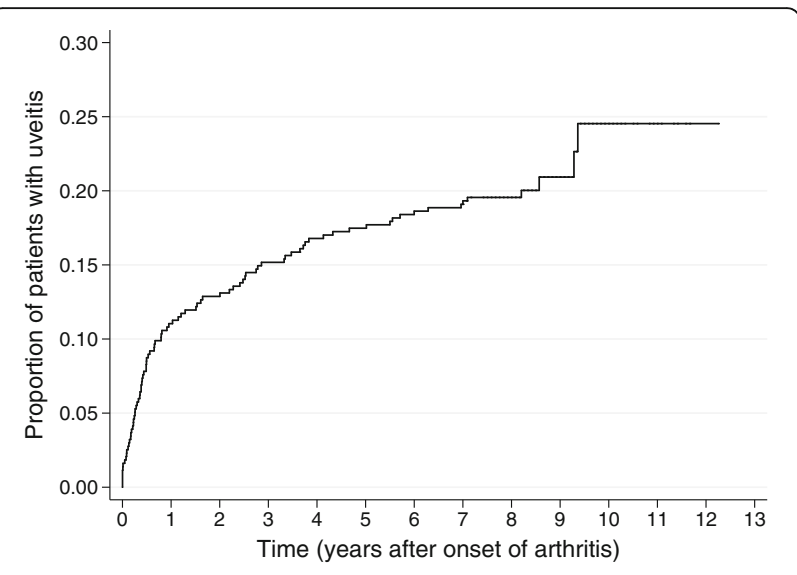

Fig. 1 Onset of uveitis in years after onset of arthritis in 435 children in the Nordic JIA cohort, including 5 children developing uveitis before onset of arthritis (time 0)

\section{Discussion}

In this Nordic multicenter JIA study, we found a high cumulative incidence of uveitis, and a geographic difference with a higher incidence in Finland compared to Norway, Sweden and Denmark. Young age at onset of arthritis, ANA and AHA were significant predictors of uveitis, but stratified for gender both young age at onset and AHA were significant predictors only in girls. Mean serum levels of AHA were higher in the uveitis group than in the children with no uveitis.

The prospective, longitudinal design and populationbased context are the strengths of this multi-center study. The proportion of children lost to follow-up was

Table 4 Baseline clinical and demographic predictors of uveitis in 435 participants in the Nordic juvenile idiopathic arthritis (JIA) cohort

\begin{tabular}{|c|c|c|c|c|c|}
\hline & \multicolumn{2}{|c|}{ No uveitis } & \multicolumn{2}{|c|}{ Uveitis } & \multirow[t]{2}{*}{ OR $(95 \% \mathrm{Cl})$} \\
\hline & $\mathrm{N}$ & n (\%) & N & n (\%) & \\
\hline Female gender & 346 & $227(65.6)$ & 89 & $59(66.3)$ & $1.0(0.6,1.6)$ \\
\hline ligoarticular onset & 346 & $168(48.6)$ & 89 & $41(46.1)$ & 0.9( \\
\hline Age at onset ( $<7$ years) & 346 & $189(54.6)$ & 89 & $64(71.9)$ & $3,3.5)$ \\
\hline ANA positive & 340 & $79(23.2)$ & 87 & $37(42.5)$ & $2.4(1.5,4.0)$ \\
\hline $\mathrm{HA}>15 \mathrm{U}$ & 112 & $14(12.5)$ & 22 & $9(40.9)$ & $4.8(1.8,13$. \\
\hline HLA-B27 positive & 325 & $62(19.1)$ & 87 & $25(28.7)$ & $1.7(1.0,2.9)$ \\
\hline $\mathrm{ESR}>20 \mathrm{~mm} / \mathrm{H}$ & 276 & $95(3$ & 78 & $34(43.6)$ & 1.5 \\
\hline CRP $>10 \mathrm{mg} / \mathrm{L}$ & 276 & $77(27.9)$ & 74 & $27(36.5)$ & $1.5(0.9,2.6)$ \\
\hline DMARD use $\leq 2$ nd visit ${ }^{a}$ & 316 & $111(35.1)$ & 34 & $14(41.2)$ & $1.3(0.6,2.7)$ \\
\hline \multicolumn{6}{|c|}{$\begin{array}{l}\text { an } 350 \text { children with no uveitis at the time of 2nd study visit, percentage of } \\
\text { DMARD used within 2nd visit (median } 13 \text { (1st q 12, 3rd q 14) months) in children } \\
\text { with no uveitis versus children with uveitis during further follow-up. } \\
\text { Odds ratio (OR) of developing uveitis calculated with logistic regression. } \\
\text { Oligoarticular onset, oligoarticular category } 6 \text { months after onset of disease, } \\
\text { according to the International League of Associations for Rheumatology } \\
\text { (ILAR) classification criteria (5); ANA antinuclear antibodies measured by } \\
\text { immunofluorescence on Hep-2 cells two positive tests taken > } 3 \text { months } \\
\text { apart in participants with one or more tests taken }\end{array}$} \\
\hline
\end{tabular}

small compared to other longitudinal studies [26-29]. A weakness is the few patients in each JIA category that made analyses of uveitis and its predictors in some of the categories less reliable. Another weakness is that information on uveitis such as differentiation between acute and chronic uveitis were registered from available ophthalmologic records by the pediatric rheumatologists and not by the ophthalmologists themselves.

The high rate of uveitis in our population is in line with previous findings in the Nordic countries [6, 11, 30, 31]. A prevalence of $8-15 \%$ was reported from Sweden [30, 32], $14-18 \%$ in northern Norway [11, 31], 9-19\% in Denmark $[33,34]$, while higher rates were previously reported from Finland $(24 \%)[6,35]$. Even though the background rate of HLA-B27 is reported to be higher in northern areas such as Finland and northern Norway [36, 37], we did not find this in our cohort from the Helsinki area in the southern part of Finland. There were also no differences in the presence of ANA between countries. The higher incidence of uveitis during the first 8 years of disease in Finland compared to the other Nordic countries in the present study may be explained by the trend of younger age at onset of arthritis in Finland and/or genetic differences. This finding is in line with the striking worldwide ethnic and genetic differences in uveitis incidence, differences beyond what can be expected by variations in patient accrual and study design. In two large studies from North America of multiethnic populations both Saurenmann et al. and Angeles-Han et al. found that uveitis was more common among Caucasians than among children of black American, Arab and Indian origin $[12,13]$. Our cohort was of mostly Caucasian origin.

In line with other studies we found that the risk of developing uveitis during the first year was more than 6 times the risk during the second year, and almost 16fold the risk during the fifth year after onset of arthritis. This underlines the need for immediate eye examination in children with onset of non-septic or non-specific arthritis even before the diagnosis of JIA is confirmed, and frequent early follow-up when a diagnosis of JIA has been established. Even though a clear majority of $82 \%$ developed uveitis within the first 4 years, our data show that uveitis may develop late in the JIA disease course. An important finding was that 4 cases of uveitis developed more than 8 years after onset of arthritis. Of these cases 2 were asymptomatic uveitis, which may not have been diagnosed without long-term screening. Zak et al. found in their 26-years follow-up of a Danish JIA cohort that both new onset of uveitis and complications may develop late [26]. Based on these data long-term ophthalmologic follow-up into adulthood must be considered.

Robust predictors of uveitis will help selecting highrisk children for frequent eye examinations to ensure early diagnosis and treatment. In acute uveitis with 
Table 5 Age at onset of arthritis, antihistone antibody levels and presence of antinuclear antibodies according to gender and presence of uveitis in 435 participants in the Nordic juvenile idiopathic arthritis (JIA) cohort

\begin{tabular}{|c|c|c|c|c|c|}
\hline & \multicolumn{2}{|c|}{ No uveitis } & \multicolumn{2}{|c|}{ Uveitis } & \multirow[t]{2}{*}{$\mathrm{p}$} \\
\hline & $n$ & Age at onset of arthritis & $n$ & Age at onset of arthritis & \\
\hline Female & 227 & $6.8(2.5,10.4)$ & 59 & $3.4(1.7,7.5)$ & $<0.001$ \\
\hline \multirow[t]{2}{*}{ Male } & 121 & $5.9(3.2,9.2)$ & 27 & $3.9(2.3,7.9)$ & 0.390 \\
\hline & $\mathrm{n}$ & Presence of ANA & $n$ & Presence of $A N A^{a}$ & \\
\hline Female & 222 & $65(29.3)$ & 59 & $27(45.8)$ & 0.016 \\
\hline \multirow[t]{2}{*}{ Male } & 118 & $14(11.9)$ & 28 & $10(35.7)$ & 0.002 \\
\hline & $n$ & AHA $\operatorname{lgM} / \operatorname{lgG~U/ml~}$ & $\mathrm{n}$ & AHA $\operatorname{lgM} / \operatorname{lgG~U/ml~}$ & \\
\hline Female & 72 & $6.9(5.2,11.4)$ & 16 & $14.2(7.2,27.9)$ & 0.003 \\
\hline Male & 40 & $7.1(4.7,11.0)$ & 6 & $8.2(4.5,11.4)$ & 0.794 \\
\hline
\end{tabular}

ANA antinuclear antibodies measured by immunofluorescence on Hep-2 cells, two positive tests taken $>3$ months apart in participants with one or more tests taken. AHA antihistone lgM/lgG antibodies $\mathrm{U} / \mathrm{ml}$, analyzed only in the Swedish and Danish cohort

a numbers (percent), analysed by Chi-square test, otherwise median (1st, 3rd quartile), analyzed with Mann-Whitney rank sum test

symptoms, the diagnosis is easy and predictors not that important, but the differentiation between acute and chronic uveitis is not always clear, and young children may have difficulties expressing complaints of a painful acute uveitis. In line with most publications we have therefore chosen to analyze predictors of all forms of JIA-associated uveitis and compared with children without uveitis $[3,12,13]$. The most consistently reported predictor of uveitis is young age at onset of arthritis. In line with Saurenmann et al. our data confirms that young age at arthritis onset implies high risk of uveitis in girls, but not in boys [38]. The predictors of uveitis are different in girls and boys, even though the rate of uveitis did not differ. This may reflect that different categories of JIA have different types of uveitis with different predicting factors. ANA is another well-documented predictor of uveitis, but this applies only to the immunofluorescence method, and not to the more automatized high-throughput method of ANA ELISA. We were not able to find the gender-specific differences of ANA that Saurenmann et al. found in their Canadian study [38], but there were few ANA positive boys with uveitis in our study.

We found increased risk of uveitis in children with high levels of antihistone antibodies. Previous findings in the Norwegian JIA cohort were now confirmed in 134 Swedish and Danish children, in whom significantly higher baseline serum levels of histone antibodies were found among those who developed uveitis compared to those who did not develop uveitis [11]. In these studies, the histone antibody levels were either borderline positive $(\geq 15 \mathrm{U} / \mathrm{ml})$ or positive $(\geq 30 \mathrm{U} / \mathrm{ml})$ according to the commercial test, however, the test and the cut-offs are established to detect drug-induced or other types of systemic lupus erythematosus in adults [23]. While the mean serum concentration of combined antihistone IgM and IgG antibodies was $19.2 \mathrm{U} / \mathrm{ml}$ in children with uveitis, and $10.2 \mathrm{U} / \mathrm{ml}$ in children without uveitis, a mean concentration of $4.3 \mathrm{U} / \mathrm{ml}$ was found in healthy children in our previous report utilizing the identical type of AHA EIA kit [11]. The reproducibility of this finding should be tested in other cohorts. Epigenetic modifications of histone such as acetylation and methylation are suggested to be involved in the pathological processes of autoimmunity [18], and may also play a role in the etiology of uveitis [39]. However, no specific intra-ocular antigen has been identified as the target of neither ANA nor AHA, and therefore their potential role in pathophysiology and etiology remains unclear. The presence of ANA immunofluorescence and AHA had similar test properties as predictors of uveitis, but with less predictive ability as the simple measure of young age at onset of arthritis. There is an ongoing discussion on classification in JIA. ANA positive young children are a quite homogeneous group regarding disease characteristics including high risk of uveitis the first 2 years after onset $[40,41]$. It is interesting that the higher risk of uveitis in girls with young age at onset, was shown also for girls with higher levels of histone antibodies in our study. Whether young girls with uveitis, presence of ANA and AHA constitutes a biological subset among children with JIA remains to be shown.

We analyzed the onset of uveitis in relation to early DMARD treatment, and found that early DMARD or methotrexate treatment did not seem to prevent later development of uveitis. The inclusion period in our cohort was too short for analyses of prevalence in different time periods, the onset of disease was in the very beginning of the era of biologic agents, and our data are therefore of limited value in clarifying any uveitisprotective potential of specific drugs or modern DMARD treatment in general. Tappeiner et al. have compared 
prevalence of uveitis in German children with JIA in two time periods up to 2013, and found a lower prevalence in the latest period when DMARDs including biologic agents were more commonly used [42]. Whether DMARDs can prevent or only postpone development of uveitis in JIA is not known.

\section{Conclusion}

We found a high prevalence of uveitis in this Nordic JIA population-based cohort. Significant predictors of uveitis were young age at onset of arthritis and presence of AHA in girls, and presence of ANA in both genders. Further long-term follow-up are needed to focus on prevalence of late-onset uveitis, presence of complications, and impact on quality of life in young adults with JIA-associated uveitis.

\section{Abbreviations}

AHA: Antihistone antibodies; ANA: Antinuclear antibodies; CHAQ: Childhood Health Assessment Questionnaire; Cl: Confidence interval; CRP: C-reactive protein; DMARD: Disease-modyfing antirheumatic drugs; EIA: Enzyme Induced Assay; ERA: enthesitis-related arthritis; ESR: Erythrocyte sedimentation rate; HLA-B27: Human leucocyte antigen B27; ILAR: International League of Associations for Rheumatology; IQR: Interquartile range; JADAS27: Juvenile Arthritis Disease Activity Score; JIA: Juvenile idiopathic arthritis; OR: Odds ratio; RF: Rheumatoid factor; SUN: Standardization of Uveitis Nomenclature

\begin{abstract}
Acknowledgements
First, we thank the children and parents participating in the study. We also thank the other members of the Nordic Study group of Pediatric Rheumatology (NoSPeR); Gudmund Marhaug in Trondheim, Freddy Karup Pedersen in Copenhagen, Pekka Lahdenne in Helsinki, Boel Anderson-Gäre in Jonköping for inspiring cooperation. Finally, we thank participating physicians contributing by collecting data; Nils Thomas Songstad, Astri Lang and Anne Elisabeth Ross in Tromsø, Kjell Berntzen and Nina Moe in Trondheim, Mikael Damgaard, Maria Ekelund and Nils Olof Jonsson, Jönköping, Anders Berner and Hans Ekström, Karlstad, Eric Ronge, Skövde, Agne Lind and Lars Hammarén, Borås, Johan Robinsson, Trollhä̈ttan and Anna-Lena Nilsson, Östersund.
\end{abstract}

\section{Funding}

This work was supported by grants from the Helse Nord Research Program, and the Grete Harbitz foundation. UiT the Arctic University of Norway funded the publication costs.

\section{Availability of data and materials}

The datasets generated and/or analyzed during the current study are not publicly available for ethical reasons, as well as privacy reasons, but are available from the NOrdic Study group of PEdiatric Rheumatology on reasonable request.

\section{Authors' contributions}

$E N, L B, A F, T H, T C, S N$, and $M R$ were involved in the conception and design of the study, and/or analysis and interpretation of data, drafting of the manuscript and revising it critically for important intellectual content. VR, KA, $M Z, S P, B S$ were involved in the acquisition of data, drafting of the manuscript and revising it critically for important intellectual content. All authors read and approved the final manuscript.

\section{Ethics approval and consent to participate}

Approval from medical research ethical committees and data protection authorities was granted according to the regulations of each participating country, in Norway from Regional Committee for Medical and Health Research Ethics NORD, number 53/96. Oral informed assent was obtained from all children. Written informed consent was obtained from parents of children aged $<16$ years and from the children if aged $\geq 16$ years of age.

\section{Consent for publication}

Not applicable.

\section{Competing interests}

The authors declare that they have no financial interests that may conflict with this manuscript.

\section{Publisher's Note}

Springer Nature remains neutral with regard to jurisdictional claims in published maps and institutional affiliations.

\section{Author details}

${ }^{1}$ Department of Pediatrics, University Hospital of North Norway, and Department of Clinical Medicine, UiT the Arctic University of Norway, Tromsø, Norway. ${ }^{2}$ Department of Ophtalmology, University Hospital of North Norway, and Department of Clinical Medicine, UiT the Arctic University of Norway, Tromsø, Norway. ${ }^{3}$ Pediatric Rheumatology Clinic, Hospital for Children and Adolescents, University of Helsinki, Helsinki, Finland.

${ }^{4}$ Department of Women's and Children's Health, Uppsala University, Uppsala, Sweden. ${ }^{5}$ Department of Pediatrics, Institute of Clinical Sciences, Sahlgrenska Academy, University of Gothenburg, Gothenburg, Sweden. ${ }^{6}$ Department of Pediatrics, Aarhus University Hospital, Aarhus, Denmark. ${ }^{7}$ Pediatric Rheumatology Clinic, Rigshospitalet Copenhagen University Hospital, Copenhagen, Denmark. ${ }^{8}$ Department of Community Medicine, UiT the Arctic University of Norway, Tromsø, Norway. ${ }^{9}$ Department of Clinical and Molecular Medicine, NTNU - Norwegian University of Science and Technology, and Department of Pediatrics, St. Olavs Hospital, Trondheim, Norway.

Received: 23 May 2017 Accepted: 11 August 2017

Published online: 18 August 2017

\section{References}

1. Skarin A, Elborgh R, Edlund E, Bengtsson-Stigmar E. Long-term follow-up of patients with uveitis associated with juvenile idiopathic arthritis: a cohort study. Ocul Immunol Inflamm. 2009;17:104-8.

2. Paroli MP, Abbouda A, Restivo L, Sapia A, Abicca I, Pivetti PP. Juvenile idiopathic arthritis-associated uveitis at an Italian tertiary referral center: clinical features and complications. Ocul Immunol Inflamm. 2015;23:74-81.

3. Heiligenhaus A, Niewerth M, Ganser G, Heinz C, Minden K. Prevalence and complications of uveitis in juvenile idiopathic arthritis in a population-based nation-wide study in Germany: suggested modification of the current screening guidelines. Rheumatology (Oxford). 2007;46:1015-9.

4. Clarke SL, Sen ES, Ramanan AV. Juvenile idiopathic arthritis-associated uveitis. Pediatr Rheumatol Online. 2016;14:27.

5. Sen ES, Dick AD, Ramanan AV. Uveitis associated with juvenile idiopathic arthritis. Nature Rev Rheumatol. 2015;11:338-48.

6. Kotaniemi K, Sihto-Kauppi K, Salomaa P, Saila H, Ristolainen L, Kauppi M. The frequency and outcome of uveitis in patients with newly diagnosed juvenile idiopathic arthritis in two 4-year cohorts from 1990-1993 and 20002003. Clin Exp Rheumatol. 2014;32:143-7.

7. Angeles-Han ST, McCracken C, Yeh S, Jenkins K, Stryker D, Travers C, et al. The Association of Race With Childhood Uveitis. Am J Ophthalmol. 2015;160:919-28.

8. Shen CC, Yeh KW, Ou LS, Yao TC, Chen LC, Huang JL. Clinical features of children with juvenile idiopathic arthritis using the ILAR classification criteria: a community-based cohort study in Taiwan. J Microbiol Immunol. 2013;46:288-94

9. Arguedas O, Fasth A, Andersson-Gare B, Porras O. Juvenile chronic arthritis in urban San Jose, Costa Rica: a 2 year prospective study. J Rheumatol. 1998;25:1844-50.

10. Berntson L, Nordal E, Aalto K, Peltoniemi S, Herlin T, Zak M, et al. HLA-B27 predicts a more chronic disease course in an 8-year followup cohort of patients with juvenile idiopathic arthritis. J Rheumatol. 2013;40:725-31.

11. Nordal EB, Songstad NT, Berntson L, Moen T, Straume B, Rygg M. Biomarkers of chronic uveitis in juvenile idiopathic arthritis: predictive value of antihistone antibodies and antinuclear antibodies. J Rheumatol. 2009;36:1737-43.

12. Saurenmann RK, Levin AV, Feldman BM, Rose JB, Laxer RM, Schneider R, et al. Prevalence, risk factors, and outcome of uveitis in juvenile idiopathic arthritis: A long-term followup study. Arthritis Rheum. 2007;56:647-57.

13. Angeles-Han ST, Pelajo CF, Vogler LB, Rouster-Stevens K, Kennedy C, Ponder $L$, et al. Risk markers of juvenile idiopathic arthritis-associated uveitis in the Childhood Arthritis and Rheumatology Research Alliance (CARRA) Registry. J Rheumatol. 2013;40:2088-96. 
14. Rekvig OP, van der Vlag J, Seredkina N. Review: antinucleosome antibodies: a critical reflection on their specificities and diagnostic impact. Arthritis Rheumatol. 2014;66:1061-9.

15. Sparchez M, Delean D, Samasca G, Miu N, Sparchez Z. Antinuclear antibody screening by ELISA and IF techniques: discrepant results in juvenile idiopathic arthritis but consistency in childhood systemic lupus erythematous. Clin Rheumatol. 2014;33:643-7.

16. Southwood TR, Malleson PN. Antinuclear antibodies and juvenile chronic arthritis (JCA): search for a specific autoantibody associated with JCA. Ann Rheum Dis. 1991;50:595-8.

17. Monestier M, Losman JA, Fasy TM, Debbas ME, Massa M, Albani S, et al. Antihistone antibodies in antinuclear antibody-positive juvenile arthritis. Arthritis Rheum. 1990;33:1836-41.

18. Picascia A, Grimaldi V, Pignalosa O, De Pascale MR, Schiano C, Napoli C. Epigenetic control of autoimmune diseases: from bench to bedside. Clin Immunol. 2015;157:1-15.

19. Meda F, Folci M, Baccarelli A, Selmi C. The epigenetics of autoimmunity. Cell Mol Immunol. 2011;8:226-36.

20. Berntson L, Andersson GB, Fasth A, Herlin T, Kristinsson J, Lahdenne P, et al. Incidence of juvenile idiopathic arthritis in the Nordic countries. A population based study with special reference to the validity of the ILAR and EULAR criteria. J Rheumatol. 2003;30:2275-82.

21. Nordal E, Zak M, Aalto K, Berntson L, Fasth A, Herlin T, et al. Ongoing disease activity and changing categories in a long-term nordic cohort study of juvenile idiopathic arthritis. Arthritis Rheum. 2011;63:2809-18.

22. Jabs DA, Nussenblatt RB, Rosenbaum JT. Standardization of uveitis nomenclature for reporting clinical data. Results of the First International Workshop. Am J Ophthalmol. 2005;140:509-16.

23. Pharmacia Deutschland GmbH DD. Varelisa Histone Antibodies, Directions for Use. Freiburg: Phadia GmbH; 2008.

24. Vandenbroucke JP, von Elm E, Altman DG, Gotzsche PC, Mulrow CD, Pocock $\mathrm{SJ}$, et al. Strengthening the Reporting of Observational Studies in Epidemiology (STROBE): explanation and elaboration. Epidemiology. 2007;18:805-35.

25. Petty RE, Southwood TR, Manners P, Baum J, Glass DN, Goldenberg J, et al. International League of Associations for Rheumatology classification of juvenile idiopathic arthritis: second revision, Edmonton, 2001. J Rheumatol. 2004:31:390-2.

26. Zak M, Pedersen FK. Juvenile chronic arthritis into adulthood: a long-term follow-up study. Rheumatology (Oxford). 2000;39:198-204.

27. Minden $K$, Niewerth $M$, Listing J, Biedermann T, Bollow M, Schontube $M$, et al. Long-term outcome in patients with juvenile idiopathic arthritis. Arthritis Rheum. 2002;46:2392-401.

28. Oen K, Malleson PN, Cabral DA, Rosenberg AM, Petty RE, Cheang M. Disease course and outcome of juvenile rheumatoid arthritis in a multicenter cohort. J Rheumatol. 2002;29:1989-99.

29. Bertilsson L, Andersson-Gare B, Fasth A, Petersson IF, Forsblad-D'elia H. Disease course, outcome, and predictors of outcome in a population-based juvenile chronic arthritis cohort followed for 17 years. J Rheumatol. 2013:40:715-24.

30. Bertilsson L, Andersson-Gare B, Fasth A, Forsblad-d'Elia H. A 5-year prospective population-based study of juvenile chronic arthritis: onset, disease process, and outcome. Scand J Rheumatol. 2012;41:379-82.

31. Moe N, Rygg M. Epidemiology of juvenile chronic arthritis in northern Norway: a ten-year retrospective study. Clin Exp Rheumatol. 1998;16:99-101.

32. Andersson GB, Fasth A, Andersson J, Berglund G, Ekstrom H, Eriksson M, et al. Incidence and prevalence of juvenile chronic arthritis: a population survey. Ann Rheum Dis. 1987;46:277-81.

33. Zak M, Fledelius H, Pedersen FK. Ocular complications and visual outcome in juvenile chronic arthritis: a 25-year follow-up study. Acta Ophthalmol Scand. 2003:81:211-5.

34. Glerup M, Herlin T, Twilt M. Remission rate is not dependent on the presence of antinuclear antibodies in juvenile idiopathic arthritis. Clin Rheumatol. 2017;17 doi:https://doi.org/10.1007/s10067-017-3540-x.

35. Kotaniemi K, Kautiainen H, Karma A, Aho K. Occurrence of uveitis in recently diagnosed juvenile chronic arthritis: a prospective study. Ophthalmology. 2001;108:2071-5.

36. Gran JT, Mellby AS, Husby G. The prevalence of HLA-B27 in Northern Norway. Scand J Rheumatol. 1984;13:173-6.

37. Kotaniemi K, Arkela-Kautiainen M, Haapasaari J, Leirisalo-Repo M. Uveitis in young adults with juvenile idiopathic arthritis: a clinical evaluation of 123 patients. Ann Rheum Dis. 2005;64:871-4.
38. Saurenmann RK, Levin AV, Feldman BM, Laxer RM, Schneider R, Silverman ED. Risk factors for development of uveitis differ between girls and boys with juvenile idiopathic arthritis. Arthritis Rheum. 2010;62:1824-8.

39. Yan B, Yao J, Tao ZF, Jiang Q. Epigenetics and ocular diseases: from basic biology to clinical study. J Cell Physiol. 2014;229:825-33.

40. Ravelli A, Felici E, Magni-Manzoni S, Pistorio A, Novarini C, Bozzola E, et al. Patients with antinuclear antibody-positive juvenile idiopathic arthritis constitute a homogeneous subgroup irrespective of the course of joint disease. Arthritis Rheum. 2005:52:826-32.

41. Ravelli A, Varnier GC, Oliveira S, Castell E, Arguedas O, Magnani A, et al. Antinuclear antibody-positive patients should be grouped as a separate category in the classification of juvenile idiopathic arthritis. Arthritis Rheum. 2011;63:267-75.

42. Tappeiner C, Klotsche J, Schenck S, Niewerth M, Minden K, Heiligenhaus A. Temporal change in prevalence and complications of uveitis associated with juvenile idiopathic arthritis:data from a cross-sectional analysis of a prospective nationwide study. Clin Exp Rheumatol. 2015;33:936-44.

\section{Submit your next manuscript to BioMed Central and we will help you at every step:}

- We accept pre-submission inquiries

- Our selector tool helps you to find the most relevant journal

- We provide round the clock customer support

- Convenient online submission

- Thorough peer review

- Inclusion in PubMed and all major indexing services

- Maximum visibility for your research

Submit your manuscript at www.biomedcentral.com/submit

) Biomed Central 